\title{
Influencing Gender Specific Perceptions of the Factors Affecting Women's Career Advance- ment Opportunities in the United States
}

By

\author{
Kevin Taliaferro, National Intelligence University
}

This research investigates the sociological, psychological, and physiological factors known to affect women's career advancement opportunities. It examines how awareness and knowledge shared through the $\$$ MeToo (hashtag Me Too) movement influenced gender specific perceptions about the factors affecting women's workplace opportunities. Finally, it recommends measures to alter the divergent gender perceptions that remain an obstacle to gender equality in the workplace.

This study was conducted because gender inequalities continue in the U.S. workplace in 2018. Currently women fail to advance in careers at the same rate as men, and they are paid $21 \%$ less for similar work with equal skills and experience. Women comprise approximately $51 \%$ of the U.S. population and $47 \%$ of the workforce, so equality would dictate a one-toone male to female ratio throughout all levels of government and private industry. The current male to female ratio in the U.S. Congress is four-to-one. The male to female executive ratio in Fortune 500 companies is three-to-one, and in the U.S. Government it is two-to-one.

To better understand the factors influencings gender inequalities in the workplace, the re- searcher conducted a mixed method experimental study. The research began with a literature review that produced enlightening results regarding the sociological, psychological, and physiological factors affecting women's career advancement opportunities.

To further examine those factors, the researcher
Men and women have significantly different perceptions of the origins, causes, and effects of the career obstacles women currently face, but the events surrounding the $\$ \mathrm{Me}-$ gender perception gap. conducted Qualitative Study 1 to determine if any significant differences existed in gender specific perceptions of male and female workplace performance, drive, confidence, competitive nature, relationships, and family responsibilities.

Study 1 results aligned with the literature review findings and confirmed both genders recognize significant gender differences exist regarding each of those factors. The unexpected discoveries were the significantly different perceptions men and women hold about the origins, causes, and effects of the factors known to impact women's career advancement opportunities.

To more deeply investigate the gender perception gap discovered in Study l, the researcher conducted a mixed method experimental study using interviews in Qualitative Study 2 to assess the significance of the differing male and female perceptions.

Keywords: Equality, Workplace, Gender, Culture, MeToo, \#MeToo

Copyright $\odot$ 2018, Kevin Taliaferro. This article is published under a Creative Commons BY-NC license. Permission is granted to copy and distribute this article for non-commercial purposes, in both printed and electronic formats 
To validate the Study 2 findings, he used surveys in Quantitative Study 3 to assess the level of impact the awareness and knowledge generated by the \#MeToo and surrounding media events had on the gender perception gap. By comparing pre- and post-treatment interview and survey data from those three studies, the researcher was able to qualify and quantify the impact awareness and knowledge shared through the \#MeToo mass media events had on gender specific perceptions of women's equality struggles in the workplace.

The literature review was the primary means used to investigate RQ1: What sociological, psychological, and physiological factors affect women's career advancement opportunities? An examination of 46 scholarly works identified three sociological factors, nine psychological factors, and two physiological factors perceived to affect women's career advancement opportunities. That examination also highlighted specific traits women exhibit within the psychological factors that negatively impact their career advancement opportunities.

Believing men and women shared more positive attitudes and perceptions about those female traits than indicated in the literature review findings; the researcher conducted Qualitative Study 1 to test his premise that there are no gender perception differences in male and female workplace performance, confidence levels, competitive nature, willingness to accept profes-

sional risks, and choices that impact careers. Study 1 also addressed RQ2: How do gender specific perceptions about male and female confidence levels, competitive nature, workplace performance, emotions, interactions, relationships, attitudes, desires, and choices impact women's career advancement opportunities? Primary data was collect through interviews with eight participants - four males and four females. Participants were randomly selected from five different industries and three primary age groups: Baby Boomers (Born 1946-1964), Generation X (Born 1965-1976), and Millennials (Born 1977-1994). An equal number of males and females was selected to gain a balanced mix of perceptions.

An unexpected discovery from Study 1 identified a gender perception gap between men's and women's views of the origins, causes, and effects of the factors influencing women's' career advancement opportunities. Viewing the gender perception gap as an obstacle to achieving true gender equality in the workplace, the researcher began to explore measures to influence and possibly reduce the gap. The timeliness and impact of the \#MeToo media events provided a unique opportunity and enabled the researcher to further examine the events' effects on gender specific perceptions of women's issues in the workplace in Study 2 and Study 3.

Qualitative Study 2 examined RQ3: How significantly did the \#MeToo media events influence gender specific perceptions about the factors affecting women's career advancement opportunities? For Qualitative Study 2, the researcher replicated the qualitative approach used in Study 1 to ensure consistency in the investigation process and most accurately assess perception changes likely generated through the \#MeToo movement. The same interview questions were asked of the same eight participants interviewed one-year prior in Study 1. Four additional participants were interviewed in Study 2 to compare consistency of answers and help identify any possible demand effect in the second interview responses, where participants may have anticipated a desired outcome and changed their answers.

For Quantitative Study 3, the researcher used two pre- and post-treatment surveys to explore RQ4: What level of impact did the \#MeToo media events have on the gender perception gap regarding the sociological and psychological factors known to affect women's career advancement opportunities? Study 3 also addressed the research hypothesis: The awareness and knowledge generated by the \#MeToo media events will strongly correlate with reductions in the gender perception gap regarding factors known to impact women's career advancement opportunities. For Quantitative Study 3, the researcher replicated portions of three national-level Pew Research Center surveys conducted between 2013 and 2015. Twenty-three Pew survey questions that fell within the scope of this research and closely aligned with study objectives were regenerated for use as a postevent collection tool. The researcher developed and launched the Study 3 surveys using the Qualtrics survey software. He anonymously invited adult business professionals from three DBA cohorts, their interested business associates, and coworkers from his organization to participate.

\section{Findings}

The Study 1 results from the qualitative interview study strongly aligned with the literature review findings and failed to support the research premise. The qualitative analysis showed men and women generally agreed women underperform, have lower confidence levels, are less competitive, more risk averse, and far more likely to make choices that neg- 
atively impact their careers. Though men and women mostly agreed there are performance differences between men and women in the workplace, the truly interesting discoveries in this study were the differing male and female perceptions of why such differences exist. Women believed the root cause of their inability to advance at the same rate as men is ultimately a result of males actively and passively discriminating against them and creating a promotion system that prevents women from advancing at the same rate as men. Men believed women have the same opportunities and as much control over their careers as men. The men alluded they have little direct bearing on women's underperformance, lower confidence levels, aversion to competition and risks, and family choices. Men perceived women in full control of their own character, emotions, and home situation and believe women are only limited by their own desires, priorities, choices, and willingness to sacrifice.

The Study 2 qualitative analysis indicated a moderate shift from divergent gender perceptions in Study 1 to convergent viewpoints in Study 2 following the \#MeToo media events. Overall, the \#MeToo media event correlated strongly with the moderate shift in men's and women's perceptions of the psychological factors known to affect women's advancement opportunities in the workplace. Though men and women still have differing views of the factors impacting women's career advancement opportunities, the majority of male and female participants expressed a positive outlook for the future, expected positive change, and embraced just and equal treatment for both genders.

In Quantitative Study 3, there were 15 fewer significant differences in the post-event results indicating the gender perception gap regarding the sociological and psychological factors known to affect women's career advancement opportunities was reduced by $43 \%$ following the \#MeToo media events. Therefore, the research hypothesis was satisfied that there is a strong correlation between the awareness and knowledge generated by the \#MeToo media events and reductions in the gender perception gap regarding factors known to impact women's career advancement opportunities.

Overall, the qualitative interview analysis indicated a moderate shift from divergent gender perceptions in Study 1 to convergent viewpoints in Qualitative Study 2 following the \#MeToo media events. The statistical results of Quantitative Study 3 showed men's perceptions changed moderately with a more positive view toward women's issues. Women's perceptions also changed moderately, but with a more negative view about workplace equality issues. Those outcomes aligned with the Qualitative Study 2 results and validated the Study 2 research findings.

\section{Conclusions}

With outcomes from three independent qualitative and quantitative investigations aligning, the researcher concluded the overall statistical results demonstrate a strong impact on men's and women's perceptions and a largely reduced gender perception gap following the \#MeToo media events. Because it is unknown if those changes are permanent, the researcher believes future research could focus on awareness, education, and accountability initiatives to more adequately address gender equality problems in the workplace and bring about lasting change.

This research demonstrates how a host of sociological, psychological, and physiological factors combine to create an atmosphere that cultivates gender inequalities. The findings are consistent that both genders perceive differences in male and female workplace performance, confidence levels, competitive nature, willingness to accept professional risks, and choices that impact careers. The researcher also discovered that men and women have completely different views of the origins, causes, and effects of the factors known to impact women's career advancement opportunities. The gender perception gap that results from men's and women's misunderstandings and misperceptions about the influencing factors and traits is problematic and clearly impedes gender equality. Though difficult to change, those misunderstandings and misperceptions must be resolved and the gender perception gap eliminated for women to achieve true workplace equality in pay, benefits, and advancement opportunities.

\section{Where to Find Out More}

For more information on this research, contact Kevin Taliaferro at kct3@mail.usf.edu or kevin.taliaferro2@dodiis.mil.

Inquiries may also be mailed to:

Kevin Taliaferro

PSC 46, Box 161

APO AE, 09469 


\section{References}

Catalyst. (2016). Pyramid: Women in S\&P 500 Companies. Retrieved from http://www.catalyst. org/knowledge/women-sp-500-companies

Center for American Women and Politics (CAWP). (2018). Women in the U.S. Congress 2018. Retrieved from http://www.cawp.rutgers.edu/women-us-congress-2018

Federal Equal Opportunity Recruitment Program (FEORP) Report to Congress-Office of Performance Management (OPM) FY14 FEORP. (2016). Retrieved from https://www.opm.gov/ policy-data-oversight/diversity-and-inclusion/ reports/feorp-2014.pdf

U.S. Bureau of Labor Statistics (US BLS). (2015). Women in the labor force: A databook. Retrieved from http://www.bls.gov/opub/reports/ womens-databook/archive/women-in-the-laborforce-a-databook-2015.pdf
U.S. Census Bureau. (2014). 2014 Population demographics. Retrieved from http://factfinder.census. gov/faces/tableservices/jsf/pages/productview. xhtml?pid=ACS_14_5YR_DP05

U.S. Department of Labor (US DoL). (2016). Breaking down the gender wage gap. Retrieved from https://www.dol.gov/wb/media/gender_wage_ gap.pdf

\section{Review}

This article was accepted under the editorial peer review option. For futher details, see the descriptions at:

http://mumabusinessreview.org/peer-review-options/

\section{Author}

Dr. Kevin Taliaferro is director of the National Intelligence University European
Academic Center at Royal Air Force Molesworth, United Kingdom. He is respon-
sible for NIU's graduate programs in Europe and manages three sites offering the
Master of Science of Strategic Intelligence degree.
He previously served as NIU's chief operating officer and chief financial officer,
where he was responsible for the university's budget planning and execution,
personnel, logistics, and facilities requirements. He is a retired United States Air
Force officer with 2,100 flying hours and extensive leadership and program man-
agement experience.

